\title{
LAERTE, MURIEL E A AUTOBIOTRANSIMAGEM
}

\author{
Wilken Figueredo Matos ${ }^{1}$ \\ Marcus Antônio Assis Lima²
}

\begin{abstract}
Resumo: Mulher trans, a brasileira Laerte Coutinho é conhecida por sua vasta obra na seara dos quadrinhos desde meados de 1970, com destaque para o seu caráter crítico a partir de uma releitura do cotidiano. Esse teor político continua sendo percebido nas tirinhas contemporâneas em que a personagem Muriel é protagonista, devido a adotar uma postura queer, buscando questionar e desnaturalizar as cis-heteronormas de gênero ainda vigentes. Além disso, é perceptível entre autora e personagem, a ocorrência de marcas que deflagram uma postura biográfica. Por isso, este trabalho pretende realizar uma queeranálise de tiras da personagem Muriel, levando em consideração os aspectos autobiográficos que se inscrevem nessas produções. A partir disso, discorreremos acerca da autobiotransimagem como uma micropolítica possível de visibilização e demarcação territorial das experiências trans. Para tanto, tomamos como subsídio teórico os postulados de Amaral \& Milanéz (2019), Arfuch (2010) e Bento (2017).
\end{abstract}

Palavras-Chave: HQ. Transgeneridade. Espaço biográfico.

\section{LAERTE, MURIEL Y LA AUTOBIOTRANSIMAGEM}

Resumen: Mujer trans, la brasileña LaerteCoutinho es conocida por su gran producción en cómics desde el 1970, con atención especial por su carácter crítico a partir de la relectura del cotidiano. Esa destreza con los contenidos políticos aún es percibida en las historietas contemporáneas en las cuales el personaje Muriel es protagonista, debido a adoptar un comportamiento queer, visando a cuestionar y desnaturalizar las cis-heteronormas de género todavía actuales. Además, es verificable la ocurrencia de rasgos que exhiben aspectos biográficos entre autora y personaje. POrtanto, este trabajo pretende realizar una queer-análisis de historietas del personaje Muriel, considerando los aspectos autobiográficos que se registran en esas producciones. A partir de eso, discurriremos sobre la autobiotransimagen como una micropolítica para hacer visible y demarcar territorios de las experiencias trans. Para ello, tomamos

\footnotetext{
${ }^{1}$ Mestrando do Programa de Pós-Graduação em Letras: Cultura, Educação e Linguagens (PPGCEL), da Universidade Estadual do Sudoeste da Bahia (UESB). Bolsista pela Fundação de Amparo à Pesquisa do Estado da Bahia (FAPESB).E-mail: wilken.matos@gmail.com.

2 Professor titular do PPGCEL. Pós-doutor em Linguagens e Representações pela Universidade Estadual de Santa Cruz (2018) e em Media \& Communications, GoldsmithsColege/Universityof London (2014). E-mail: malima@uesb.edu.br.
} 
como soporte teórico los postulados de Amaral \& Milanéz (2019), Arfuch (2010) y Bento (2017).

Palavras-Chave: Cómic. Transgeneridad. Espacio biográfico.

Olha: gênero e sexualidade são coisas independentes. Pode-se usar vestido e salto alto e ser hétero, assim como se pode ser gay e vestir calças, coturno...

(Muriel)

(Ou Laerte?)

Dentre os diversos imaginários que percorrem a sociedade, têm-se o de que as histórias em quadrinhos (doravante HQ) são textos exclusivamente voltados ao universo infantojuvenil; seja pelo uso do diminutivo - inho; seja pelo pensamento de que elas tratarão de temas menos densos, desconectados da realidade. No entanto, é importante destacar que, além desse entretenimento infantil, as HQs se constituem como materialidades, plurais, relevantes linguística e socialmente; não só devido a esses textos comportarem um sincretismo entre as linguagens verbal e não-verbal na profusão de seus discursos, como também quanto aos próprios discursos difundidos nessas composições estarem diretamente ligados à factualidade social (LIMA, 2020). Por meio de uma HQ, realizam-se íntimas ligações entre aspectos temporais, econômicos e políticos. A propósito, as HQs emergem como modalidades textuais junto ao contexto da Revolução Industrial (KLAWA; COHEN, 1972), período que demarca uma série de mudanças históricas e implicações na ordenação social, como a substituição de um paradigma baseado no "encadeamento lógico-linear que caracterizava a visão medieval do universo" (p. 104), por um modelo de realidade fragmentada, produto da separação entre os universos público e privado, os quais formatarão novos modos de o homem urbano, entre outros, trabalhar e produzir seu lazer.

As HQs são, então, tomadas como objetos culturais intimamente ligados a questões temporais, econômicas e políticas. Suas composições em quadros podem inclusive ser consideradas como uma referência à fragmentação produzida pela modernidade, contexto em que as HQs têm sua gênese. Para além disso, elas aderem a um compromisso crítico, abordando desde costumes da sociedade burguesa, até a formação e atuação de suas 
instituições, com vistas a processos de conscientização, de desalienação. É nessa perspectiva que podemos, num salto crônico para a segunda metade do século XX, fazer referência à produção dos quadrinhos underground, que "tinham como tema a sexualidade, a violência, os hippies, a droga e a ecologia", apresentando "estilos e propostas visuais variados, utilizando uma estética caricatural e realista" (MAGALHÃES, 2009, p. 4). Esses quadrinhos surgem, primeiramente, nos Estados Unidos como um elemento contestatório ao teor reacionário de censura e repressão às diversas transformações sociais pelas quais o país passava.

Essas mudanças constituíam-se, em determinada medida, como respostas positivas pelo enfrentamento de movimentos políticos de grupos marginalizados contra regimes hegemônicos. Nesse sentido, recordamos os movimentos homossexuais nos Estados Unidos como políticas que requeriam o debate acerca dos discursos sobre a (homos)sexualidade propalados pelos dispositivos medicinal, religioso e jurídico. Essa pauta é adotada por diversos intelectuais e adentra o ambiente acadêmico como teoria. A partir daí, a Teoria Queer se funda, à luz das premissas de Foucault e Derrida, como um instrumental político e metodológico que busca, dentre outros, desnaturalizar padrões; questionar a lógica binária cis-heteronormativa; ao tempo em que ressignifica discursos normatizadores e os lugares onde eles são inscritos, os corpos.

Para Jean-Jacques Courtine, “o corpo é uma invenção teórica recente". O autor afirma isso de modo a contrastar o "papel secundário" que o corpo tinha, posto que, filosoficamente, o que se apresentava como relevante era o espírito humano. A propósito, o corpo ganha dimensão epistemológica a partir de estudos psicanalíticos, quando Freud alega a necessidade do corpo como suporte para a enunciação do inconsciente. Eis, então, o corpo como “objeto de pesquisa” (AMARAL; MILANEZ, 2019, p. 19). No entanto, Amaral e Milanez, a partir de Courtine, afirmam mudanças quanto ao estatuto corporal quando rememoram políticas feministas que reclamaram para si a autonomia do corpo. Isso faz com que deixemos de enxergá-lo somente como desvelamento do inconsciente, mas também como uma estratégia de resistência frente às instâncias de poder hegemônico ou, como diriam os autores, "o corpo aparece como objeto de protesto circunscrito naquelas 
condições históricas" (AMARAL; MILANEZ, 2019, p. 19). Ainda de acordo com os autores

o corpo nos anos 1970 estava inserido nesse exercício de forças que lutava para se impor diante da sociedade repressora. As práticas de gritar o pertencimento do corpo a cada sujeito e de fazer dele o que bem lhes conviesse configura uma relação de poder, sendo um instrumento importante de libertação (AMARAL; MILANEZ, 2019, p. 19).

Desse modo, o corpo valida-se como ferramenta de emancipação, um artefato garantidor de uma autonomia em relação aos discursos representativos do poder hegemônico. O corpo é, assim, um mecanismo construtor de realidades dissidentes, haja vista ele materializar os segmentos marginalizados e silenciados historicamente. Por conta disso, o corpo assume posição central não só em discussões acadêmicas, mas nas tensões promovidas por disputas territoriais advindas das identitárias.

Outros autores declaram os corpos como essas materialidades políticas de resistência em função de eles atuarem como espaços de inconformidade quanto às inscrições discursivas dominantes que aspiram a uma disciplinarização, prescrição comportamental que se dá, principalmente, por meio do gênero. Sobre isso, Berenice Bento, seguindo a perspectiva de Judith Butler, afirma que "podemos analisar gênero como uma sofisticada tecnologia social heteronormativa, operacionalizada pelas instituições médicas, linguísticas, domésticas, escolares e que produzem constantemente corpos-homens e corpos-mulheres" (BENTO, 2017, p. 83). Em outras palavras, o gênero é uma categoria de análise originada por processos, métodos, meios e instrumentos socialmente produzidos com o intuito de agenciar corpos resultantes de contínuas repetições para adoção de uma dada imagem que corresponda a um ideal de masculino ou de feminino como implicação de um sexo biológico. Segundo esse prisma,

antes de nascer o corpo já está inscrito em um campo discursivo determinado. Ainda quando se é uma promessa, um devir, há um conjunto de expectativas estruturadas numa complexa rede de pressuposições 
sobre comportamentos, gostos e subjetividades que acabam por antecipar o efeito que se supunha causa (BENTO, 2017, p. 84).

No entanto, o regime que prescreve essas pressuposições tem suas bases numa proposição discursiva definida pela cis-heteronormatividade, que atribui caráter de abjeto aos corpos que não se adéquam às suas normas; é o caso dos corpos transexuais, considerados como os corpos pertencentes a um determinado sexo biológico, mas que não se conformam com essa atribuição e projetam comportamentos numa performatividade de gênero pressuposta para o sexo biologicamente oposto. Esses corpos foram, e continuam sendo constantemente, taxados como anomalias, disforias, como corpos patológicos, na medida em que se apresentam como uma adversidade à lógica cisheteronormativa que prescreve a performance de gênero como implicação da inscrição do sexo biológico.

No entanto, esses corpos podem ser percebidos de diversas maneiras. Por um lado, percebemos uma potência, uma autoridade que produz discursos reacionários os quais se valem de estratégias que reiteram a normatividade. Nesse sentido, não só a colocação da transexualidade como patologia, mas a sua identificação como diagnóstico imprescindível para a ocorrência de mudanças de sexo, em que se verifica a transformação do corpo como uma adequação ao que se entende como masculino ou feminino (BITENCOURT; SANTOS, 2019, p. 64). É a insistência de um pensamento que toma o corpo de modo sexualizado e, em função da constante binária, produz diversas formas de violência ao promover não só silenciamentos, mas verdadeiros apagamentos dessas identidades ambíguas, fluidas, da sociedade como um todo.

A partir disso, podemos lembrar Letícia Lanz, que nos alerta:

ser uma pessoa transgênera é ser um não-ser. Um não-ser é alguém que não é, institucionalmente falando. Alguém que, mesmo tendo existência material, não constitui uma identidade socialmente reconhecida e legitimada, isto é, devidamente inserida na matriz cultural de inteligibilidade. Juridicamente, um não-ser não constitui um "sujeito de direito" estando sujeito, portanto, a levar sua existência à margem das garantias e proteções legais 
asseguradas aos sujeitos de direito, que são aqueles sujeitos reconhecidos e protegidos pela lei (LANZ, 2016, p. 206).

Em outras palavras, uma pessoa transgênera é oprimida, invisibilizada, para ser esquecida. É um processo no qual se deslegitima a existência em termos totais, desde o plano da ideia até o da materialidade.

Por outro lado, a transexualidade e sua concretização nos corpos trans compõem um "exercício da liberdade, torna o corpo uma arte transgressiva aos moldes conformistas da norma vigente, pois têm a potência de desestruturar as certezas do binarismo fundante da sociedade heteronormativa" (CHAVES, 2015 apud BITENCOURT; SANTOS, 2019, p. 70). Os corpos trans, de acordo com Bitencourt \& Santos, "referem-se às multiplicidades, trânsitos identitários, /.../ redefinições de papéis de gênero, estética, linguagem" (BITENCOURT; SANTOS, 2019, p. 58); caracterizam-se por um aspecto dinâmico, em total contraponto às ideias de identidades estáticas. Bento reforça esse pensamento ao dizer que para a transexualidade "há uma pluralidade de interpretações e de construções de sentidos para os conflitos entre o corpo e a subjetividade". A autora vai além e afirma, ainda, que "o que faz um sujeito afirmar que pertence a outro gênero é um sentimento" (BENTO, 2017, p. 41). Essas colocações nos concedem a possibilidade de abordar o corpo trans como uma ruptura, mas, principalmente, como uma subjetividade. É imprescindível que seu entendimento se dê pela própria experiência e sensação do corpo em questão. Por exemplo, há corpos desejantes de procedimentos cirúrgicos; no entanto, há também os mais polimorfos, aqueles que borram cada vez mais a cis-heteronorma e aspiram à ambivalência como constitutivo.

Levando em consideração o que foi abordado até aqui, poderíamos nos perguntar: O que fazer para garantir a existência, digna, dessa experiência identitária que é a transexualidade? Com o intuito de responder a essa questão, Berenice Bento afirma que "no processo de aceitação e de construção de uma nova identidade, é importante a capacidade de elaborar uma história, e o encontro com outras histórias facilita esse processo" (BENTO, 2017, p. 222). Ao dizer isso, a autora faz referência às narrativas de vida enunciadas pelos 
próprios corpos trans e coletadas para a confecção de sua pesquisa que, em seguida, tornou-se o livro $A$ (re)invenção do corpo.

Para compreender melhor a dimensão social-política dessas narrativas, recorramos à Leonor Arfuch. A autora, em $O$ espaço biográfico: dilemas da subjetividade contemporânea (2010), declara que a aparição da primeira pessoa como elemento caracterizador dos textos biográficos se deu há aproximadamente duzentos anos; ela constrói um percurso no intento de uma genealogia do espaço biográfico. Arfuch menciona um novo paradigma de leitura, que substitui a leitura oral pela silenciosa, produto de uma divisão de espaços e conteúdos em públicos e privados, o que por sua vez possibilitará uma nova manifestação de escrita, marcado por um "eu". Essas escritas, a princípio, diziam respeito a memórias de personagens públicas, com seus feitos relevantes, como guerras e revoluções, a partir de um olhar subjetivo. Assim, partindo de Habermas para explorar a proliferação de subjetividades em textos distintos, a autora entende que os leitores desenvolvem relações afetivas positivas com essas escritas, levando em consideração que a narração de um conteúdo da ordem do privado efetiva uma aproximação, tendo em vista que o narrado está a serviço de uma representação do outro. Essa circunstância, conforme a autora, "era a mudança substancial nas relações entre autor, obra e público" (ARFUCH, 2010, p. 46), posto que os textos passaram a ser meios para a promoção de um conhecimento de si a partir da narrativa do "eu" narrado; mas também uma tática para tornar pública a esfera do privado. Após mencionar Rousseau como fissura de modelos da exposição do "eu" devido a um exagero de privacidade, a autora instala a voz narrativa como fator decisivo de autoconhecimento e autorregulação do leitor. E, ainda, traz à tona uma crítica a Lejeune e sua proposta de autobiografia como um processo referencial, no qual o leitor percebe uma equivalência entre os fatos narrados e os fatos vividos pelo autor.

As formas de se relacionar com o leitor por meio de distintos textos literários, faz a autora retomar postulados bakhtinianos como o dialogismo e a intertextualidade, levando em consideração um projeto de alteridade nos textos, ao mesmo tempo em que não existiria um texto inteiramente novo, sempre fazendo referência a outro advindo de experiências vividas, ainda que elas sejam recortadas e, a partir deles, a autora recupera a ideia de "valor 
biográfico" como forma de se estabelecer uma aproximação entre o real e o fictício (ARFUCH, 2010, p. 71). É aí, então, que Arfuch entra em defesa de uma proposta de espaço biográfico como "um vazio constitutivo" (2010, p. 80). Esse espaço não se delinearia em um gênero específico, mas seria um entre-lugar, pois toda escrita apresentaria marcas dessa criação de um "eu", com vistas ao surgimento e libertação de identidades sociais à luz da alteridade. Com isso, identificamos essas narrativas, situadas num espaço biográfico, como uma tecnologia da subjetividade e uma micropolítica de insurgência e coexistência de experiências identitárias distintas.

Se retomarmos tudo que vimos até aqui, verificamos o espaço biográfico como uma potência das subjetividades; os corpos, mais especificamente os corpos trans, como lugares de inconformidade quanto a discursos hegemônicos e as HQs como objetos culturais que respondem a uma dada realidade, fragmentada, e que, por alicerçarem-se em critérios econômicos, políticos e sociais, estão a serviço de uma intervenção crítica na sociedade. Tendo em vista que a produção de quadrinhos do Brasil foi influenciada pela cultura underground, podemos abordar a produção da cartunista Laerte Coutinho, hoje mulher trans, como uma proposta crítica, mas que se perfaz pela intersecção entre a modalidade textual adotada e a postura biográfica que adota em suas produções ao tratar corpos trans com discursos que se aproximam do seu. Essa intersecção permitirá defendermos a noção de "autobiotransimagem".

Pai de três filhos, cartunista, roteirista e chargista, Laerte teve uma vida relativamente agitada desde cedo. Embora não tenha concluído, aos 18 anos de idade, ingressou no curso de Jornalismo na Universidade de São Paulo (USP); tendo, no ano seguinte, adentrado a graduação em Música, na mesma instituição de ensino, sem, também, tê-la concluído. Nos anos de 1970, filiou-se ao Partido Comunista Brasileiro (PCB) e dedicou-se ao Movimento Democrático Brasileiro (MDB). Vencedor de prêmios como o Melhor Roteirista Nacional no 1o HQ Mix, colaborou como roteirista de diversos programas televisivos conhecidos, entre eles TV Pirata, TV Colosso e Sai de Baixo. Laerte também contribuiu com diversos impressos brasileiros, como O Pasquim, Zero Hora e Correio Braziliense e se firmou como um dos mais relevantes artistas brasileiros devido a tirinhas como Piratas do Tietê. 
Além disso, o artista é responsável pela criação da personagem Hugo, um rapaz crossdresser, que, posteriormente, se revela transgênero e passa a atuar como sujeito enunciador de um discurso queerstionador, desestabilizador das cis-heteronormas. Hugo, então, torna-se Muriel. Há um interesse em particular por essa personagem, tendo em vista que ela, a princípio, desempenharia um papel de alter ego de seu criador, sendo, posteriormente, considerado como uma tecnologia de gênero que se inscreveu no corpo Laerte. Isso é perceptível a partir dos contrapontos entre as experiências que compõem os dados biográficos do corpo autor e as da personagem; mas também pelo entrecruzamento discursivo de ambos a partir de uma queer-análise contrassexual.

Embora as primeiras tirinhas com a participação de Hugo datem de 1993, sua aparição como crossdresser somente aconteceu nos idos dos anos 2000. Por sua vez, Laerte, nascido em 1951, inicia seu processo de reflexão acerca de sua experimentação identitária de gênero em 2004, mas tem esse processo interrompido devido à morte do filho mais novo, em um acidente de carro. Apenas em 2009 a cartunista assume publicamente sua transexualidade, quando já havia publicado tirinhas do Hugo travestindo-se de mulher. De início, encontramos um paralelo entre a personagem e o corpo Laerte no que tange ao período de assunção da experimentação de gênero trans. Há um intervalo considerável de tempo para instituir-se como tal; ainda que isso não represente problema, visto que "as pessoas podem se descobrir e/ou se revelar transgêneras em qualquer estágio ou circunstância de vida: na infância, na adolescência, no início da fase adulta, na meia ou já idosos. Podem ser solteiros, casados, divorciados e terem ou não filhos" (LANZ, 2016, p. 210).

Vejamos as tirinhas que se seguem e comparemo-nas com trechos de falas enunciadas pelo corpo Laerte em entrevistas concedidas para a confecção de seu documentário Laerte-se. 

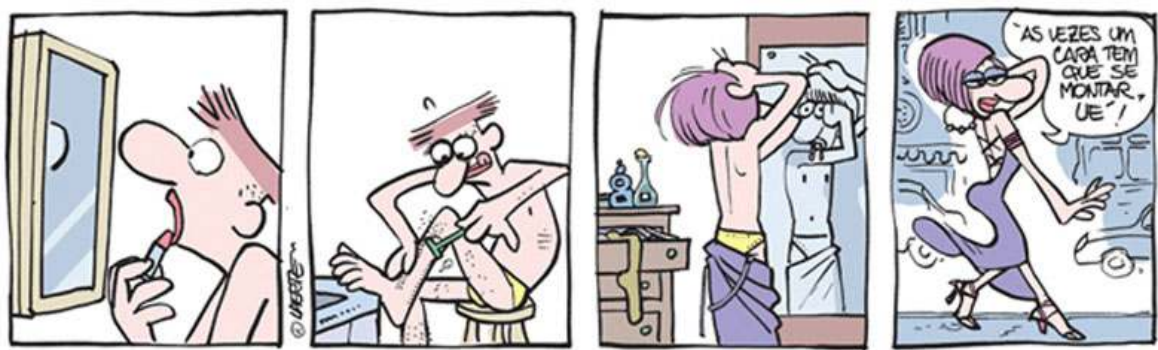

Fonte: https://www.itaucultural.org.br/ocupacao/laerte/oa-laerte/?content_link=3 Acesso em: 24 ago. 2020.

A imagem acima revela uma personagem do sexo masculino depilando-se e, em seguida, vestindo-se de mulher, o que em uma cultura cisheteronormativa é considerado como um comportamento feminino. Essa tira mantém um paralelo com a seguinte fala do documentário: “ $A$ primeira roupa que eu usei foi uma roupa que eu tirei, na verdade, que foram os meus pelos. Mais que usar calcinha... Eu vi outra pessoa no espelho, não acreditava, fiquei pulando"(LAERTE-SE, 2017). Além disso, a partir de Amaral e Milanez (2019, p. 25), baseados em Foucault, percebemos a tira não só utilizando graficamente o desenho de um espelho, como servindo-se da projeção de um. "O espelho, como sabemos reflete a imagem do objeto diante dele", é por meio desse objeto que os corpos que se situam em sua frente adquirem a leitura "de seus contornos corpóreos" (AMARAL; MILANEZ, 2019, p. 25); logo, o espelho é um objeto que viabiliza não só uma apreensão sensorial visual do corpo, como produz parte de sua significação. É o espelho que outorga o conhecimento do corpo que se coloca diante dele. No entanto, essa noção de espelho está a serviço de uma dupla dimensão, a do espelho como objeto da tira que significa o corpo Muriel para a própria personagem; mas também a da própria tira como espelho do corpo Laerte, ao passo em que esse espelho

reflete um corpo utópico, ou seja, um corpo sem lugar, mas que irradia todos os lugares possíveis. O espelho, também, pode ser considerado um lugar heterotópico. Para Foucault, as heterotopias são "espaços diferentes, desses outros lugares, uma espécie de contestação simultaneamente mítica e real do espaço em que vivemos" (FOUCAULT, 2006, apud AMARAL; MILANEZ, 2019, p. 26). 
Por meio dessas premissas, podemos afirmar que o corpo Laerte traz consigo uma consciência de um corpo significado, porém não materializado socialmente. A utilização das tiras como espelhos do corpo Laerte institui-se como uma antecipação de seu corpo trans. As tiras posteriormente servirão como tecnologias de inscrição discursiva que materializarão o corpo trans Laerte. A isso, acresce o fato de o corpo situar-se na ambivalência, ao dizer "às vezes, um cara tem que se montar!" (negritos nossos), demarcando um sexo biológico macho, porém com uma expressão de gênero feminina consciente da fissura realizada. Dessa forma, esse corpo usa da imagem para construir a narração de um "eu” transgênero que, por sua vez,

considera-se a resistência à normalização dos gêneros como uma estética da existência, cuja potência de criação está na multiplicidade performativa que opera como uma alternativa ao biopoder, utilizando das atribuições de anormalidade conferidas a estes corpos como uma afirmação política que causa fissuras na inquestionabilitidade dos gêneros (BITENCOURT, SANTOS, 2019, p. 59-60).

Imagem 2:

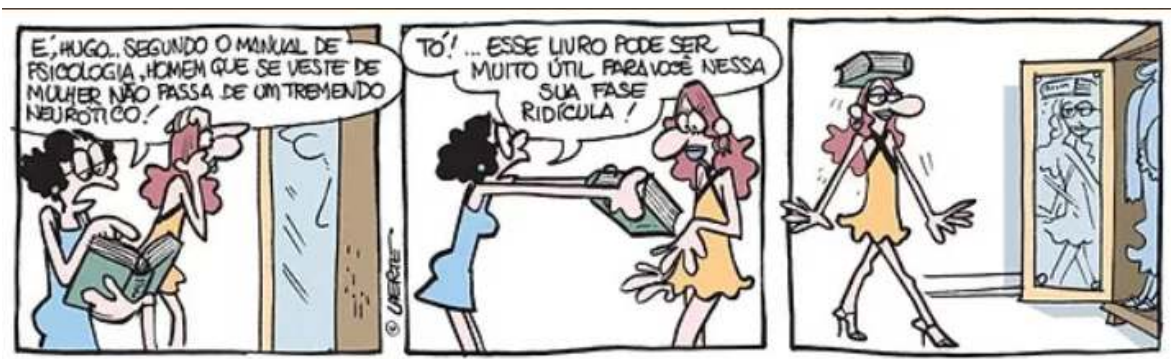

Fonte: https://jornalivrosliterar.wixsite.com/jornalivros/single-post/2015/10/09/ElaLaerte Acesso em: 24 ago. 2020.

A imagem 2 reafirma o caráter das tiras em sua dupla dimensão de espelho (inclusive, não são raras as tiras que trazem Hugo ou Muriel diante de espelhos). Além disso, a tira não só corrobora a ideia de desestabilização das normas de gênero (quando ironiza o "Manual de Fisiologia”, metáfora para as prescrições performáticas de gênero cis-heteronormativo), mas também 
apresenta uma crítica aos corpos normatizados que busca "fazê-la desistir inteiramente de ser ela mesma para tornar-se uma 'cópia fiel' de algum modelo de conduta imposto pela sociedade" (LANZ, 2016, p. 207). Outrossim, acerca dessa tira, é a equivalência discursiva no que se refere ao que o corpo Laerte pronuncia em depoimento: Eu deixava o Hugo se travestir, se maquiar. Era uso do cômico, ele era visto como ridículo"(LAERTE-SE, 2017).

\section{Imagem 3:}

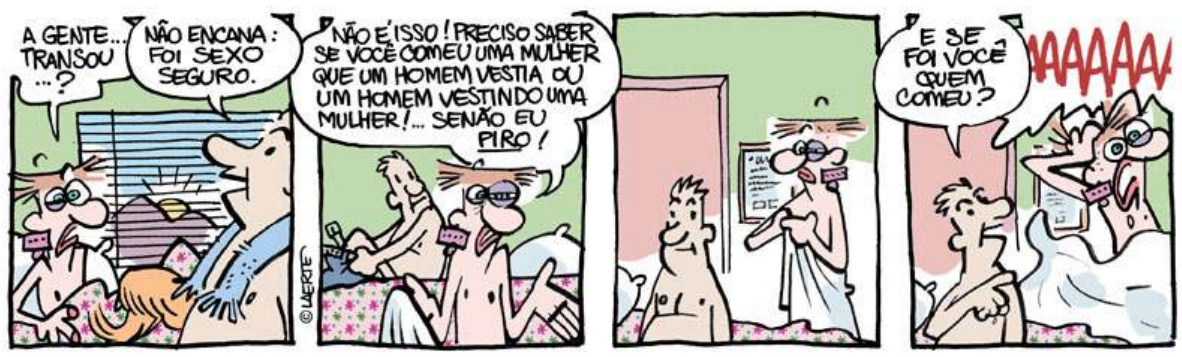

Fonte: https://www.itaucultural.org.br/ocupacao/laerte/oa-laerte/?content_link=3 Acesso em 24 ago. 2020.

Imagem 4:

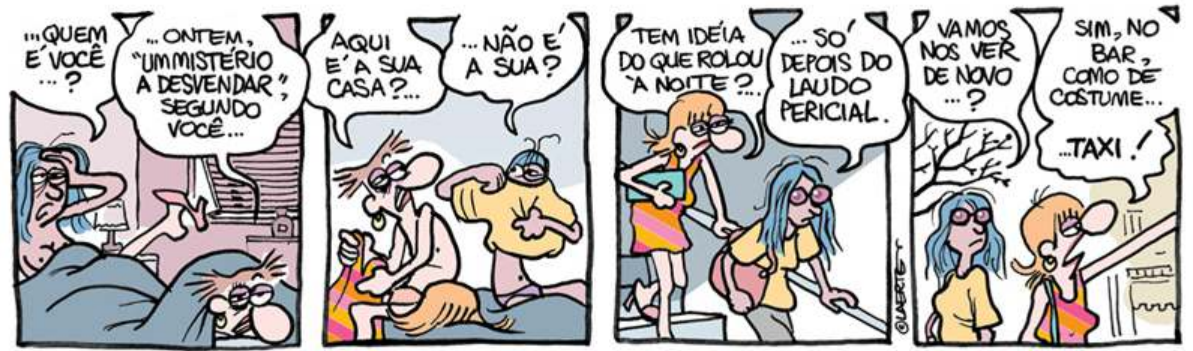

Fonte: https://www.itaucultural.org.br/ocupacao/laerte/oa-laerte/?content_link=3 Acesso em 24 ago. 2020.

As imagens 3 e 4 realizam um entrecruzamento ideal para a exploração do que sugerimos como autobiotransimagem. Primeiramente, verificamos a autorrepresentação do corpo Laerte em concomitância com sua sexualidade, conforme mencionada em seu documentário. Perguntado sobre 
suas paixões, o corpo Laerte fala que acabara de viver algo "muito rápido, coisa de um mês /... /. Era uma mulher, homossexual /... E isso era uma coisa interessante, porque ela se interessou pela mulher que eu sou" (LAERTE-SE, 2017). Esse depoimento revela um aspecto biográfico que confere uma sexualidade livre, fissura de uma

outra ideia estapafúrdia [que] é /.../ a de que orientação sexual e identidade de gênero são uma mesma e única coisa, quando também já se demonstrou exaustivamente se tratar de duas coisas inteiramente distintas. Ou seja, pessoas transgêneras não são gays ou lésbicas "mais afetadas", mas pessoas cujo comportamento de gênero apresenta não conformidade em relação ao modelo binário homem-mulher em vigor na sociedade (LANZ, 2016, p. 208).

Nas imagens, Muriel não desfaz sua identidade de gênero, que é o modo como performatiza e reifica seus comportamentos voltando-se para distintas masculinidades e feminilidades; pelo contrário, mesmo nos primeiros quadrinhos aparece maquiado e com brincos. No entanto, a maneira como Muriel é narrada visualmente, assim como suas falas, sugerem distintos movimentos sexuais, com parceiros de ambos sexos e posições que escapam à pseudo-lógica da passividade para a feminilização trans. Isso coaduna com o que Arfuch levanta acerca de seu projeto de espaço biográfico quando afirma ser possível explicar sua concepção de sujeito e identidade da seguinte maneira:

Um sujeito não essencial, constitutivamente incompleto e, portanto, aberto a identificações múltiplas, em tensão com o outro, o diferente, através de posicionamentos contingentes que é chamado a ter. [...] esse sujeito, no entanto, é suscetível de autocriação (ARFUCH, 2010, p. 80).

Além disso, percebemos o "potencial subversivo" dos corpos trans, tanto Muriel quanto Laerte, "uma vez que deslocam as noções de 'real'(verdade) e de 'fictício' (mentira)" (BENTO, 2017, p. 104) também ambiguamente, posto que essas noções de factualidade e ficção podem se 
ancorar nas pretensões da cis-heteronorma de construir um discurso verdadeiro, fundante, natural; mas também borram o limite de referencialidade e de imaginação que circunscreve a produção dos quadrinhos. É a constatação de que "o corpo transexual põe essa verdade em um labirinto" (BENTO, 2017, p. 104).

Imagem 5:
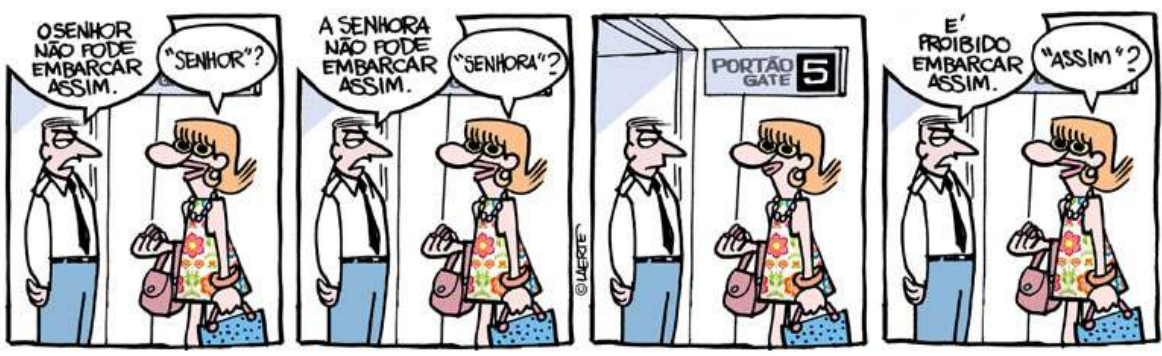

Fonte: https://www.itaucultural.org.br/ocupacao/laerte/oa-laerte/?content_link=3 Acesso em 24 ago. 2020.

Imagem 6:
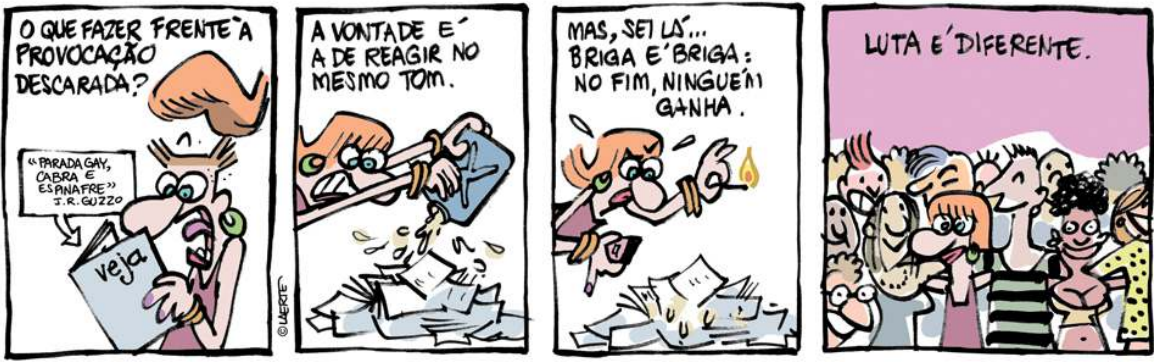

Fonte: https://monografias.brasilescola.uol.com.br/arte-cultura/a-construcao-dosujeito-transexual-feminino-em-tirinhas-de-laerte-coutinho. htm Acesso em: 24 de ago. 2020.

As últimas imagens reiteram a proposta autobiotransimagética devido a elas também estarem em consonância com o discurso experienciado e produzido pelo corpo Laerte, que afirma "de jeito nenhum pode deixar $o$ corpo de lado" ao ser perguntado sobre a possibilidade de ser mulher fora do corpo; assim como quando declara "não estou construindo uma identidade 
feminina, é que eu não preciso de identidade nenhuma" (LAERTE-SE, 2017). Essas falas revelam o teor político de resistência do corpo trans, aquele que age "teimando em existir sem ser 'autorizado a existir"' (LANZ, 2016, p. 206); da mesma forma causa tensionamentos "nos dispositivos regulatórios /.../que se podem oportunizar a constituição de novas políticas sexuais e o agenciamento de novas culturas dissidentes da cultura normativa heterossexual" (BITENCOURT; SANTOS, 2019, p. 72).

Observando as imagens 5 e 6, verificamos os efeitos mencionados, tendo em vista que Muriel questiona, desestabiliza normas, linguísticas e de performance cis-heteronormativa, a fim de evidenciar as formas como seu corpo delas escapa, e naturalmente o de Laerte (corpos que são um só). Além disso, também constatamos um processo de alinhamento discursivo que se nega à violência produzida hegemonicamente, na medida em que se propõe a luta como diferente, como "uma política focada nas relações de poder e nas brechas dos regimes de verdade que poderiam se transformar em resistências, contrapor-se a perspectiva hegemônica e dar ênfase a experiência social da abjeção" (BITENCOURT; SANTOS, 2019, p. 69).

Além do exposto, vimos que essas propostas se aproximam, flertam e transam com os postulados do filósofo espanhol Paul B. Preciado, ao defender um modelo contrassexual no qual não só o gênero se materializa nos corpos (PRECIADO, 2017, p. 29), mas também estabelece a decadência da ideia de Natureza como regime de inscrição desses corpos. Não se trata de um agenciamento de novas configurações de subjetividade, pelo contrário, uma percepção do corpo como instrumento político capaz de dinamitar as normas disciplinares de gênero.

A partir do que foi mencionado por meio de todos os exemplos de imagens e discussões, podemos afirmar a noção de autobiotransimagem como um maquinário de deslocamento contrassexual. Ela é a autorrepresentação, em narrativas imagéticas, de um sujeito dissidente de alteridade experimentacional. Isso significa projetar-se em textos imagéticos; em corpos ambíguos, provocadores e questionadores; que constituam suas subjetividades pautadas nas experiências. 


\section{Referências}

AMARAL, Ricardo; MILANEZ, Nilton. "Hoje eu vou mudar!" Do corpo trans/travesti, da música e de outras coisas. In: MILANEZ, Nilton; AMARAL, Ricardo; MOURA, Ismarina (Org.). Transexualidades: o que pode o corpo? João Pessoa: Marca de Fantasia, 2019. p. 14-33.

ARFUCH, Leonor. O espaço biográfico: dilemas da subjetividade contemporânea. Tradução Paloma Vidal. Rio de Janeiro: EdUERJ, 2010.

BENTO, Berenice. A reinvenção do corpo - sexualidade e gênero na experiência transexual. 3. ed. Salvador: Editora Devires, 2017.

BITENCOURT, Kueyla de Andrade; SANTOS, Lucas Caires. Corpos trans, discursividade e matriz heteronormativa: a despatologização como estética da existência. In: MILANEZ, Nilton; AMARAL, Ricardo; MOURA, Ismarina (Org.). Transexualidades: o que pode o corpo?- João Pessoa: Marca de Fantasia, 2019. p. 58-74.

KLAWA, Laonte; COHEN, Haron. Os quadrinhos e a comunicação de massa. In: MOYA, Álvaro de. Shazam. São Paulo: Perspectiva, 1972.

LANZ, Letícia. Ser uma pessoa transgênera é ser um não-ser. In: Revista Periódicus: Corpo, política, psicologia e psicanálise: a produção de saber nas construções transidentitárias. Salvador, vol. 1, n. 5, p. 205-220, mai./out. 2016. Disponível

em: https://portalseer.ufba.br/index.php/revistaperiodicus/article/view/17188/11 343 Acesso em: 19 ago. 2020.

LAERTE-SE. Direção de Lygia Barbosa da Silva e Eliane Brum. São Paulo: True Lab, 2017. (101 min.), son., color.

LIMA, Marcus A. Assis. O entretenimento no jornalismo impresso: contratos e cenografias. Vitória da Conquista: Edições UESB, 2020.

MAGALHÃES, Henrique. Indigestos e sedutores: o submundo dos quadrinhos marginais. In: Culturas Midiáticas. Revista do Programa de Pós-Graduação em Comunicação da Universidade Federal da Paraíba. João Pessoa, vol. II, n. 1, jan./jun. $2009 . \quad$ Disponível em: https://periodicos.ufpb.br/index.php/cm/article/view/11688/6714 Acesso em: 20 ago. 2020.

PRECIADO, Paul B. Manifesto contrassexual. Tradução de Maria Paula Gurgel Ribeiro. São Paulo: n-1 edições, 2017.

Recebido em 31 de Agosto de 2020.

Aceito em 30 de outubro de 2020. 